\section{International Scientific Journal Theoretical \& Applied Science}

Inna Aleksandrovna Serebryanik

Candidate of technical sciences, associate professor, Associate Professor of the Department of World economy Irkutsk National Research Technical University nasamolet@yandex.ru

Darya Maksimovna Zolotuhina student Irkutsk National Research Technical University

SECTION 4. Computer science, computer engineering and automation.

\title{
PRESENTATION: BASIC CONCEPTS
}

Abstract: Given the notion of presentation. Analyzed the main types of presentations. Selected criteria for successful presentations.

Key words: presentation, pitch, TED, business presentation, slide.

Language: Russian

Citation: Serebryanik IA, Zolotuhina DM (2016) PRESENTATION: BASIC CONCEPTS. ISJ Theoretical \& Applied Science, 04 (36): 43-45.

Soi: http://s-o-i.org/1.1/TAS-04-36-8 Doi: crossef http://dx.doi.org/10.15863/TAS.2016.04.36.8

\section{ПРЕЗЕНТАЦИЯ: БАЗОВЫЕ ПОНЯТИЯ}

Аннотация: Дано понятие презентация. Проанализированы основные виды презентаций. Выделены критерии успешных презентаций.

Ключевые слова: презентация, питч, TED, бизнес-презентация, слайд.

Слово презентация в переводе с латинского означает представление/предъявление.

Презентация, в идеале, это не театр одного актера. Это шоу/театр. Декорации - слайды, реквизит - презентуемый товар, и актеры выступающие спикеры.

Оптимальное время для презентации - 10 минут. Именно в течении этого времени можно эффективно удерживать внимание слушателя. Если ваша презентация требует более долго выступления, по ходу презентации меняйте спикеров. Есть еще одна теория, которая говорит, что оптимальное время для презентаций -18 минут.

Есть мнение, что лучшие спикеры пользователи Twitter, потому как они умеют выразить свою мысль в 140 символах.

Новизна - вот что способно привлечь внимание к презентации. Мозг человека никогда не сможешь проигнорировать новость. Если вы не можете предложить новость - предложите оригинальный подход.

Создание идеальной презентации требует много времени. На создание 20минутной презентации Apple уходит в среднем 250 часов. Никогда нельзя выступать экспромтом, даже если у вас за плечами опыт публичных выступлений. Если вы только начинающий спикер, то попробуйте снять себя на видео, чтобы оценить то, что вы делаете со стороны.

Презентации могут быть 2-х видов:

1. Для выступления;

2. Для прочтения.

Презентация в формате «для прочтения» должна быть самодостаточной и не требовать никаких пояснений.

Самые сложные презентации в бизнесе - это презентации перед инвесторами. Есть даже термин «питч» - презентации проекта потенциальному инвестору/покупателю /будущему партнеру (от англ. термина pitch, «бросок», пришедшего из бейсбола). Отмечают, что успешный питч - это наука, а не искусство.

Инвесторы оценивают презентацию по 13 критериям:

1. Перспективность возможностей;

2. Сила духа предпринимателя;

3. Страстность;

4. Образование;

5. Стиль;

6. Опыт работы со стартапами;

7. И др.

Сегодня наиболее эффективными являются четыре формы презентации: 
$\checkmark$ 3-«минутный» питчинг B2DM - Business to department marketing. Презентация проекта руководителю компании)

$\checkmark$ 6-«минутная» презентация В2С -

Business-To-Consumer. Рассчитана на конечного потребителя;

$\checkmark$ 10-«минутная» презентация В2В -

Business-To-Business Презентация одной компании другой компании;

$\checkmark$ 12-«минутная» презентация B2S -

Business-To-Salesman. Презентация, рассчитанная на дистрибьюторов.

Кармин Галло (известный консультант по коммуникациям), проанализировав 500 презентаций TED, дает несколько советов спикерам:

1. Быть восторженным и страстным, открытым, уязвимым и застенчивым;

2. Рассказать три истории. Это способно тронуть любого слушателя;

3. Неустанно практиковаться. Презентации, у которых более 10-15 млн. просмотров, начинаются после 200-й репетиции;

4. Рассказывать что-то новое;

5. Добавлять интересные детали;

6. Использовать юмор, не добавляя шуток. Юмор понижает защиту слушателей и делает их более восприимчивыми;

7. Придерживаться правила 18 минут. Специалисты говорят, что после 18-й минуты происходит «когнитивное отставание».

8. Меньше текста, больше изображений;

9. Внутри каждой презентации может быть несколько слайдов-шоков. Это резкая картинки, какое-то неожиданное заявление. Это позволит слушателем держать презентацию в фокусе. Также можно использовать пустые слайды, чтобы слушатели сделали акцент именно на ваших словах, а не графике.

В начале презентации всегда нужно представиться и рассказать о чем ваша презентация, и лишь потом переходить к содержательной части.

В процессе презентации спикер может использовать точеные раздражители, которые привлекут внимание слушателей. Профессор на филфаке, где $80 \%$ обучающие девушки, когда видел, что внимание аудитории потеряно, не меняя тона, говорил: «А теперь я расскажу вам, как не залететь...».

Помните, что люди читают всегда быстрее, чем вы говорите. Потому пока они не дочитают, они не будут вас слушать. Следовательно, не вставляйте много текста на слайд.

5 секунд требуется слушателю, чтобы составить впечатление о слайде.

Последовательность создания презентации:
1. Представить картину в целом. Не открывать никакую программу по созданию презентаций. Поставить цель и определить средства ее достижения;

2. Составить план выступления. Такой план поможет вам понять, какие из ваших слов нуждаются в сопровождении презентации;

3. Сделать бумажный эскиз презентации;

4. Оформить презентацию с помощью программного средства;

5. Отшлифовать полученную презентацию;

Общие правила для деловых презентаций:

1. Титульный слайд должен полностью захватить внимание слушателя;

2. Не перегружать презентацию слайдами. 7-10 оптимальный объем. Каждый из них должен запоминаться. Есть правило: Одна идея - один слайд. НО! Лучше сделать 100 легких слайдов, чем 10 перегруженных;

3. Слайд должен быть виден в среднем 25 секунд;

4. Оглавление стоит делать, если в презентации более 50-ти слайдов;

5. Не использовать слишком мелкий шрифт. Лучше меньше слов, но написанных крупными буквами. Гай Кавасаки (создатель концепции «евангелизма» в Apple) призывает использовать в презентациях 30 кегль. Этот кегль подходит и для тех, у кого хорошее зрение и для тех, кто носит очки;

6. Использовать только мягкие, не раздражающие слушателей цвета;

7. Заполнять слайд информацией равномерно;

8. Некоторые специалисты деловых презентаций не рекомендуют использовать пункты и подпункты. Например, ни в одной презентации Apple или TED вы их не встретите;

9. Использовать строгие шрифты;

10. Не использовать более 3-4 цветов. Если вы делаете презентацию в другой стране, изучите, что означают те или иные цвета. Например, в Японии, белый цвет - цвет смерти, а в красный в Китае - символ процветания;

11.Если презентация объемная, нужно делать слайды-заглушки или слайды-дзен (слайды настроения). На слайдах-заглушках может быть название тематического раздела, чтобы слушатели не теряли нить повествования;

12. Логотип - в правый верхний угол слайда;

13. Слайды - это не шпаргалка для спикера. Спикер не должен их читать;

14. Графика должна быть только высокого разрешения;

15.Всегда делайте раскрадровку, чтобы знать после каких слов идет какой слайд;

Типовые ошибки презентаций:

1. Отсутствие единого стиля; 


\begin{tabular}{|c|c|c|c|c|c|c|}
\hline Impact Factor: & $\begin{array}{l}\text { ISRA (India) } \\
\text { ISI (Dubai, UAF } \\
\text { GIF (Australia) } \\
\text { JIF }\end{array}$ & $\begin{array}{l}=1.344 \\
=0.829 \\
=0.564 \\
=1.500\end{array}$ & $\begin{array}{l}\text { SIS (USA) } \\
\text { PИНЦ (Russia } \\
\text { ESJI (KZ) } \\
\text { SJIF (Morocco }\end{array}$ & $\begin{array}{l}=\mathbf{0 . 9 1 2} \\
=\mathbf{0 . 2 3 4} \\
=\mathbf{1 . 0 4 2} \\
=\mathbf{2 . 0 3 1}\end{array}$ & $\begin{array}{l}\text { ICV (Poland) } \\
\text { PIF (India) } \\
\text { IBI (India) }\end{array}$ & $\begin{array}{l}=6.630 \\
=1.940 \\
=4.260\end{array}$ \\
\hline
\end{tabular}

2. Плохо подобранные иллюстрации;

3. Плохая верстка;

4. Плохо расставленные приоритеты.

Что касается голоса. Ели вы хотите звучать убедительно, сделайте так, чтобы ваш голос шел из грудной клетки, а не из горла.

Сегодня создание презентаций стало бизнесом. В России, например, известна компания «Блокбастер». Компаний очень креативна. Например, одному из своих клиентов она предложила презентацию в один слайд с надписью ERROR, для привлечения внимания к качеству сервиса для клиентов супермаркета. Компаний готовит в среднем 70 презентаций в год. Бюджет каждой от $5000 \$$ и выше. Интересна история появлении и продвижения компании. Стартовый капитал составлял 5000 рублей. Ребята просто купили стекленные банки в Ikea и перец. Перец засыпали в банки и приклеивали этикетку «Добавить перчинки в презентацию». Банки развешивали на двери потенциальных клиентов. На хорошую рекламу отреагировали Philip Morris, Альфа-банк, Мегафон... Сегодня вреди клиентов компании Pfizer, Tetrapak, Mail.ru, Unilever, Аэроэкспресс. Прибыль «Блокбастер» 20 млн.рублей в год. Штат 70 человек.

\section{References:}

1. (2016) - Prezentacii TED Available: http://www.ted.com/ (Accessed: 10.04.2016).

2. (2016) - Kollekcija uchebnyh prezentacij Available: $\quad$ http://uchebnyeprezentacii.rf/ (Accessed: 10.04.2016).

3. (2016) - 30 sovetov kak provesti uspeshnyj pitch. Available: https://pronewsblog.ru/tips/30-sovetov-kak-provestiuspeshnyy-pitch (Accessed: 10.04.2016).

4. (2016) V stile Stiva Dzhobsa: kak osnovat' biznes na jeffektivnyh prezentacijah. Available: http://biz-anatomy.ru/vse-stati/istoriiuspekha/177-istorii-uspekha-biznes-naprezentatsiyakh (Accessed: 10.04.2016).

5. Gallo K (2015) Otzyvy i recenzii o knige Prezentacii v stile TED. 9 priemov luchshih v mire vystuplenij. - Moscow: Al'pina Pabli-sher, 2015. - $256 \mathrm{p}$.
6. Donovan D (2013) Vystuplenie v stile TED. Sek-rety luchshih $\mathrm{v}$ mire vdohnovljajushhih pre-zentacij. - Moscow: Mann, Ivanov i Ferber, 2013. - 208 p.

7. Kapterev A (2012) Masterstvo prezenacii. Kak sozdavat' prezentacii, kotorye mogut izmenit' mir. - Moscow: Mann, Ivanov i Ferber, 2012. $-336 \mathrm{p}$.

8. Majorkin S (2015) 30 pravil ideal'noj prezentacii. - Moscow: AGC.

9. Morton S (2016) Laboratorija prezentacij. Formula ideal'nogo vystuplenija. - Moscow: Al'pina Pablisher, 2016. - 260 p.

10. Ostroumova M (2016) Uspeshnaja prezentacija: ot postanovki celi $\mathrm{k}$ tonkostjam dizajna. Available: (Accessed: 10.04.2016). 